УДК 615.322

\title{
ОСОБЕННОСТИ СОДЕРЖАНИЯ УРСОЛОВОЙ И ОЛЕАНОЛОВОЙ КИСЛОТ У ДИКОРАСТУЩЕЙ PRUNELLA VULGARIS (LAMIACEAE) И ВЫРАЩЕННОЙ В КЛИМАТИЧЕСКОЙ КАМЕРЕ
}

\author{
(C) Н.В. Петрова*, А.Л. Буданцев, Н.А. Медведева, А.Л. Шаварда
}

\author{
Ботанический институт им. В.Л. Комарова РАН, ул. профр. Попова, 2, Санкт- \\ Петербург, 197376 (Россия), e-mail: NPetrova@binran.ru
}

\begin{abstract}
Черноголовка обыкновенная (Prunella vulgaris L., Lamiaceae) является источником разнообразных вторичных метаболитов, например, тритерпеновых соединений. Мажорными среди тритерпеноидов P. vulgaris являются урсоловая и олеаноловая кислоты, обладающие широким спектром биологической активности. В данном исследовании была изучена динамика содержания урсоловой и олеаноловой кислот на разных стадиях онтогенеза черноголовки обыкновенной, произрастающей в природных ценопопуляциях (Ленинградская обл.) и в климатической камере. Получены данные по содержанию исследуемых кислот на четырех стадиях онтогенеза: вегетация, бутонизация, цветение и плодоношение. В растениях P. vulgaris, произрастающих в хвойно-мелколиственном лесу и на разнотравно-злаковом газоне, на стадии вегетации зафиксировано минимальное содержание урсоловой и олеаноловой кислот; содержание исследуемых кислот достигло своего максимума к стадии цветения, а к стадии плодоношения их концентрация несколько снизилась. Показано, что в растениях P. vulgaris, выращенных в климатической камере, урсоловая и олеаноловая кислоты на стадиях вегетации и бутонизации не обнаружены. Исследуемые кислоты у растений, выращенных в искусственных условиях, начинают накапливаться лишь к цветению и достигают своего максимума к плодоношению.

Ключевые слова: урсоловая кислота, олеаноловая кислота, Prunella vulgaris L., Lamiaceae.
\end{abstract}

\section{Введение}

Prunella vulgaris L. - черноголовка обыкновенная - является многолетним травянистым растением, широко распространенным в Европейской России, на Каказе, в Сибири и на Дальнем Востоке. Обладая широким спектром биологической активности, P. vulgaris применяется в народной и традиционной медицине [1].

В надземной части черноголовки обыкновенной выявлен богатый набор вторичных метаболитов, в том числе тритерпеноидов [2], доминантными компонентами которых являются урсоловая и олеаноловая кислоты (рис. 1, 2). Эти тритерпеновые соединения проявляют высокую активность при болезнях печени и как диуретическое средство [3, 4], а также являются одними из активных компонентов в диабетических препаратах из-за способности понижать сахар в крови [5].

Содержанию урсоловой и олеаноловой кислот в экстрактах P. vulgaris посвящено много работ [6-9], имеются также сведения о содержании этих тритерпеноидов в разных частях P. vulgaris [10], подробно изучена их сезонная динамика в соцветиях [11]. Разработаны приемы выращивания P. vulgaris в условиях гидропоники, направленные на максимальный выход урсоловой и олеаноловой кислот [12]. Нами ранее

Петрова Наталья Валериевна - кандидат биологических наук, научный сотрудник лаборатории растительных ресурсов; e-mail: NPetrova@binran.ru Медведева Нина Анатольевна - кандидат биологических наук, доцент, старший научный сотрудник лаборатории растительных ресурсов

Буданцев Андрей Львович - доктор биологических наук, ведущий научный сотрудник лаборатории растительных ресурсов

Шаварда Алексей Леонидович - кандидат биологических наук, старший научный сотрудник лаборатории аналитической фитохимии сообщалось, что содержание урсоловой и олеаноловой кислот в листьях $P$. vulgaris изменяется со сменой фенофаз растения [13]. В частности, показано, что в листьях P. vulgaris в период вегетации урсоловая и олеаноловая кислоты обнаруживаются в минимальных концентрациях, в период бутонизации содержание этих кислот значительно увеличивается, достигая максимума своего содержания к периоду цветения, а к фазе плодоношения содержание исследуемых кислот снижается [13].

\footnotetext{
* Автор, с которым следует вести переписку.
} 


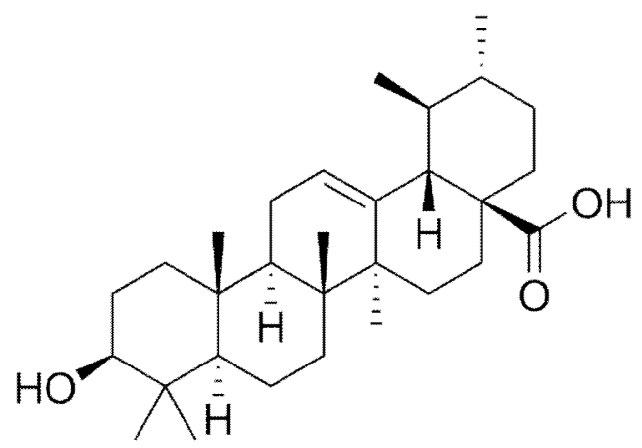

Рис. 1. Урсоловая кислота

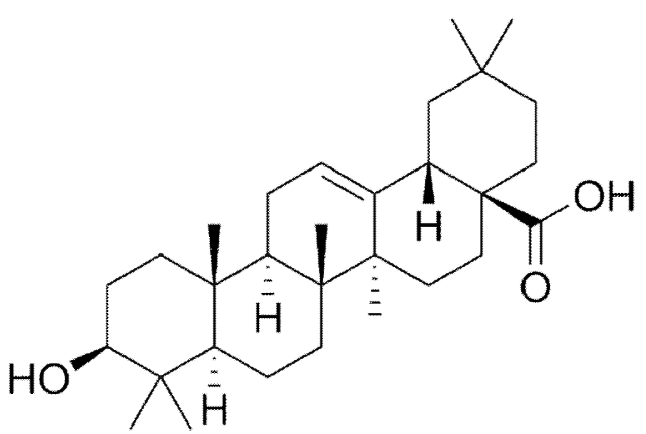

Рис. 2. Олеаноловая кислота

Сезонный ритм развития P. vulgaris в природе был изучен рядом авторов $[14,15]$, однако ход развития черноголовки обыкновенной в искусственных условиях ранее не описывался.

Целью данного исследования было изучение динамики накопления урсоловой и олеаноловой кислот в листьях P. vulgaris в условиях климатокамеры в сравнении с образцами, собранными в естественных условиях обитания.

\section{Материал и методы}

Исходным материалом для опытного выращивания P. vulgaris в климатической камере (образец №1) послужили эремы (далее - семена), собранные в 2012 г. на территории Научно-опытной станции (НОС) БИН РАН «Отрадное» (Ленинградская область, Приозерский р-н). После сбора семена хранились в бумажных пакетах при комнатной температуре. Перед посевом они прошли стратификацию в течение трех месяцев при температуре $-3{ }^{\circ} \mathrm{C}$. Семена (по 30 штук в двух повторностях) высаживали в универсальный грунт для выращивания рассады (торф, дерново-подзолистая почва, перлит, измельченный известняк, азот, фосфор, калий, микроэлементы). Полив осуществляли по мере высыхания грунта. Растения выращивали в течение двенадцати месяцев в климатической камере «Sanyo MLR-351H» (Япония) в следующих режимах: первые два месяца - при освещении с 08-00 до 20-00 тремя лампами FL 40SS-W/37 по 5000 1х каждая и при температуре $+16{ }^{\circ} \mathrm{C}$; с третьего месяца до окончания опыта растения находились при круглосуточном освещении и при температуре $+20^{\circ} \mathrm{C}$.

В естественных условиях обитания $P$. vulgaris листья собирали на разнотравно-злаковом газоне в парке БИН РАН (Санкт-Петербург) (образец №2) и на территории НОС «Отрадное» в хвойномелколиственном лесу (образец №3) в 2010-2014 гг.

Для определения содержания урсоловой и олеаноловой кислот до цветения растения отбирали листья из третьей пары укороченного побега, а в генеративном состоянии - из третьей от соцветия пары листьев. Листья фиксировали в метаноле в виалах с завинчивающимися крышками (Agilent, US) при комнатной температуре в течение 24 ч, затем хранились в холодильнике. Метанольный экстракт упаривали на роторном испарителе, предварительно извлекая из него растительный материал, который взвешивали после высушивания в термостате при $100{ }^{\circ} \mathrm{C}$. Виалы с экстрактивом хранили в холодильнике. Количественная оценка содержания исследуемых кислот проводилась методом внутреннего стандарта. В каждую виалу вносили 50 мкг трикозана путем добавления 50 мкл $0,1 \%$ р-ра стандартного соединения в пиридине. Полученную смесь подвергали силилированию. Из известных триметилсилильных реагентов был выбран BSTFA ([N,O-бис-(триметилсилил)трифторацетамид]) (Supelco (US). В виалы, содержащие исследуемый образец с добавленным стандартом, вводили 20 мкл BSTFA; для обеспечения достаточной полноты протекания реакции силилирования виалы выдерживали в течение 15 мин при температуре $100{ }^{\circ} \mathrm{C}$ в специальном термоблоке с последующим хромато-масс-спектрометрическим анализом. Образцы исследовали на хромато-масс-спектрометре фирмы Agilent Maestro 7820 с масс-селективным детектором Agilent 5975 D. Хроматографическое разделение проводили на капиллярной колонке AgilentHP-5MS длиной 30 м, внутренним диаметром 0,25 мм и толщиной пленки неподвижной фазы 0,25 мкм в режиме программирования температуры. Программа: $70^{\circ} \mathrm{C}-6^{\circ} \mathrm{C} /$ мин $-325^{\circ} \mathrm{C}(50$ мин), газ-носитель - гелий. Анализ проводился в режиме постоянства скорости газового потока через колонку (1 мл/мин). Температура испарителя $300{ }^{\circ} \mathrm{C}$, 
деление потока при вводе проб $1: 20$. Сканирование масс-спектров от 50 до 1050 а.е.м. со скоростью 2 скана/c. Хроматограммы образцов регистрировали по полному ионному току.

Идентификацию урсоловой и олеаноловой кислот в образцах проводили на основании сравнения полученного масс-спектра с данными MC-библиотеки NIST 2011. Из-за отсутствия стандартных образцов урсоловой и олеаноловой кислот их количественный анализ проводили в режиме semi-quant (без учета коэффициентов чувствительности).

\section{Результаты и обсуждение}

По наблюдениям в климатической камере через 17-20 дней после посадки семян Prunella vulgaris началось массовое появление проростков. Прорастание семян надземное. Из микропилярного отверстия первым появляется корешок, короткий гипокотиль выносит на поверхность почвы семядоли. Черешки семядолей $0,1-0,3$ см дл., светло-зеленые. Пластинки семядолей $0,3-1,0$ см дл., 0,3-0,8 см шир., округлой формы, светло-зеленые, голые. Главный корень до 4,0 см дл. с отходящими от него боковыми корнями первого порядка. Через 30-35 дней стали появляться первые настоящие листья. К 60-му дню опыта начали появляться новые проростки P. vulgaris (примерно 10\% от количества, заложенного в опыте), которые в последствии догнали в своем развитии проростки, появившиеся почти на два месяца раньше. К 60-70 дню опыта подавляющее большинство растений черноголовки были представлены укороченными розеточными вегетативными побегами с 2-3(5) парами супротивно расположенных цельных листьев на черешках; в пазухах листьев заложены боковые почки. В таком состоянии растения пребывали примерно 240 дней (почти 8 месяцев), не увеличивая количество пар листьев, а только незначительно увеличивая их размеры. Поскольку из литературных данных известно, что черноголовка обыкновенная зацветает на 3-4-й год, то для ускорения прохождения онтогенеза на 60-й день опыта мы перешли на круглосуточное освещение в климатокамере. На 100-й день опыта были взяты листья из 3-й пары для определения содержания олеаноловой и урсоловой кислот. На 250-й день опыта было отмечено образование соцветий, а к 300-му дню опыта - цветение. Опыление производилось искусственным путем. Массовое плодоношение зафиксировано через 10-15 дней.

Следует отметить, что размеры и масса листьев черноголовки обыкновенной, взятых для экстракции в хвойно-мелколиственном лесу, превышали аналогичные показатели для растений, выросших на разнотравно-злаковом газоне. Однако средние значения этих параметров для растений из обеих естественных ценопопуляций сопоставимы с таковыми у растений, выращенных в климатической камере. Так, средняя длина (см) листьев P. vulgaris, собранных в естественных условиях, на момент плодоношения $-3,03 \pm 0,34$, средняя ширина (см) - 1,66 $\pm 0,25$, а для листьев, собранных к климатической камере $-2,25 \pm 0,41$ и $1,73 \pm 0,26$ соответственно. Средняя масса (г) листовых пластинок до экстракции для естественных условий составля-

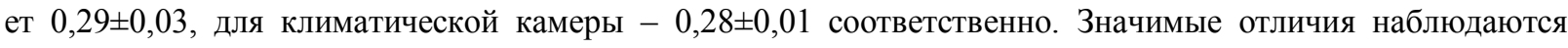
в средней массе листьев после экстракции: масса (гр) листовой пластинки $P$. vulgaris после экстракции из естественных ценопопуляций составляет в среднем $0,01972 \pm 0,01$, а у $P$. vulgaris, выращенной в климатокамере, $-0,00522 \pm 0,01$ соответственно.

Концентрация олеаноловой и урсоловой кислот в листьях $P$. vulgaris, выросших в естественных условиях, претерпевала изменения с течением онтогенеза (табл. 1 и 2). При увеличении концентрации от минимальной на стадии вегетации, через стадию бутонизации, содержание исследуемых кислот достигло своего максимума к стадии цветения, а к стадии плодоношения их концентрация несколько снизилась. Наибольшая концентрация исследуемых кислот наблюдалась на стадии цветения: урсоловой кислоты 7500 ppm у растений из образца №3 и 3600 ppm у растений из образца №2; олеаноловой кислоты - 3300 и 1000 ppm соответственно. По сравнению со стадией вегетации содержание урсоловой и олеаноловой кислот у $P$. vulgaris, выросших на разнотравно-злаковом газоне, увеличилось более чем в два раза, а у $P$. vulgaris из хвойно-мелколиственного леса - более чем в 10 раз. Нами не отмечена четкая зависимость концентрации исследуемых кислот у P. vulgaris, выросших на разнотравно-злаковом газоне и в хвойномелколиственном лесу. Так, на стадии вегетации содержание урсоловой кислоты выше у растений из образца №2, тогда как на стадии цветения получены противоположные результаты.

Наши данные согласуются с результатами Y. Chen и соавторов [11], которые описали сезонную динамику содержания урсоловой и олеаноловой кислот в надземной части P. vulgaris на материале, собранном в провинции Henan и выращенном в провинции Anhui (Восточный Китай). Так, авторами сообщается, 
что наибольшая концентрация урсоловой и олеаноловой кислот достигается в период полного цветения (1,77 и 0,65 мг/г соответственно), несколько ниже концентрация исследуемых кислот в период плодоношения (1,32 и 0,39 мг/г) и минимальная концентрация была зафиксирована ими у вегетирующих растений (0,98 и 0,21 мг/г). Похожие результаты получили и P. Liu с соавторами [10], однако, по их наблюдениям, содержание урсоловой и олеаноловой кислот в листьях P. vulgaris несколько выше на стадии плодоношения (2,9 и 0,3 мг/г соответственно), чем на стадии цветения (2,7 и 0,2 мг/г).

Таблица 1. Динамика содержания урсоловой кислоты в листьях Prunella vulgaris L. (ppm)

\begin{tabular}{c|c|c|c|c}
\hline \multirow{2}{*}{ Образцы } & \multicolumn{4}{|c}{ Содержание урсоловой кислоты (ppm) } \\
\cline { 2 - 5 } & Вегетация & Бутонизация & Цветение & Плодоношение \\
\hline 1 & - & - & 1000 & 9000 \\
2 & 1000 & 1400 & 3600 & 1600 \\
3 & 700 & 800 & 7500 & 1300 \\
\hline
\end{tabular}

Примечание. Прочерк означает, что соединение не обнаружено.

Таблица 2. Динамика содержания олеаноловой кислоты в листьях Prunella vulgaris L. (ppm)

\begin{tabular}{c|c|c|c|c}
\hline \multirow{2}{*}{ Образцы } & \multicolumn{3}{|c}{ Содержание олеаноловой кислоты (ppm) } \\
\cline { 2 - 5 } & Вегетация & Бутонизация & Цветение & Плодоношение \\
\hline 1 & - & - & 900 & 2000 \\
2 & 120 & 500 & 1000 & 400 \\
3 & 300 & 800 & 3300 & 1900 \\
\hline
\end{tabular}

Примечание. Прочерк означает, что соединение не обнаружено.

Несколько иные результаты получены нами для экземпляров P. vulgaris, выросших в климатокамеpe. На стадии вегетации и бутонизации ни урсоловая, ни олеаноловая кислоты не были обнаружены. К стадии цветения содержание олеаноловой кислоты составляло 900 ppm, а урсоловой - 1000 ррт. Концентрация исследуемых кислот достигла своего максимума к стадии плодоношения и составила 2000 и 9000 ррm соответственно.

Если сравнивать дикорастущие и культивируемые в климатокамере растения, то очевидно, что наибольшая разница в содержании урсоловой и олеаноловой кислот наблюдается у растений в стадии вегетации и бутонизации: от их отсутствия у особей, выращенных в климатической камере, до 1400 и 800 ррm соответственно у экземпляров, выросших в природе. Возможно, это связано с тем, что на момент бутонизации дикорастущим растениям минимум 3-4 года, а растениям, выращенным в климатокамере - меньше года, точнее, около 250 дней, т.е. процессы синтезирования вторичных метаболитов у данных образцов находились на разных стадиях. Истинные причины остаются пока неясными, однако довольно резкая динамика содержания исследуемых кислот свидетельствует о том, что существуют как внутренние, так, вероятно, и внешние факторы, определяющие сложный ход накопления урсоловой и олеаноловой кислот. К плодоношению содержание исследуемых кислот становится выше или, по крайней мере, сравнительно сопоставимым независимо от условий существования растений. Тем не менее для установления факторов, определяющих довольно свободную (и различную у разных растений этого вида) динамику накопления урсоловой и олеаноловой кислот, необходимы дальнейшие исследования.

\section{Заключение}

Содержание урсоловой и олеаноловой кислот у растений, выращенных в условиях климатической камеры, увеличивается от цветения к плодоношению. У растений, выросших в естественных условиях, содержание исследуемых кислот увеличивается от бутонизации и достигает своего максимума к цветению, затем к периоду плодоношения содержание урсоловой и олеаноловой кислот заметно снижается.

Работа выполнена в рамках государственного задания № 01201255610 Ботанического института им. В.Л. Комарова РАН, при поддержке программы фундаментальных исследований Отделения биологических наук РАН на 2015 г. «Рачиональное использование биологических ресурсов России: фундаментальные основы управления». Проект «Растительные ресурсы России: сосудистые растения и водоросли-макрофитьл». 


\section{Список литературы}

1. Растительные ресурсы России: Дикорастущие цветковые растения, их компонентный состав и биологическая активность. Т. 4. Семейства Caprifoliaceae - Lobeliaceae. СПб., 2011. 630 с.

2. Cheung H.Y., Zhang Q.F. Enhanced analysis of triterpenes, flavonoids and phenolic compounds in Prunella vulgaris L. by capillary zone electrophoresis with the addition of running buffer modifiers // J. Chromatogr. A. 2008. N1213. Pp. 231-238.

3. Головкин Б.Н., Руденская Р.Н., Трофимова И.А., Шретер А.И. Биологически активные вещества растительного происхождения: в 3 т. М., 2001. Т. II. 764 с.

4. Liu J. Pharmacology of oleanolic acid and ursolic acid // J. Ethnopharmacol. 1995. Vol. 49. N2. Pp. 57-68.

5. Liu H.X., Shi Y.H., Wang D.X., Yang G.L., Yu A.M., Zhang H.Q. MECC determination of oleanolic acid and ursolic acid isomers in Ligustrum lucidum Ait. // J. Pharm. Biomed. Anal. 2003. Vol. 32. N3. Pp. 479-485.

6. Du H., Chen X. Q. A comparative study of the separation of oleanolic acid und ursolic acid in Prunella vulgaris by high-performance liquid chromatography and cyclodextrin-modified micellar electrokinetic chromatography // J. Iran. Chem. Soc. 2009. Vol. 6. N2. Pp. 334-340.

7. Liao L., Liu L., Guo Q.Sh., Wang Z.Y., Chen Y.N. Morphological and chemical variation of Prunella vulgaris populations from different location of China // Chin. Herb. Med. 2010. Vol. 2. N4. Pp. 305-311.

8. Chen Y., Guo Q., Kiu L., Liao L., Zhu Z. Influence of fertilization and drought stress on the growth and production of secondary metabolites in Prunella vulgaris L. // J. Med. Plants Res. 2011. Vol. 5. N9. Pp. 1749-1755.

9. Chen Y., Zhu Z., Guo Q., Zhang L., Zhang X. Variation in concentrations of major bioactive compounds in Prunella vulgaris L. related to plant parts and phenological stages // Biol. Res. 2012. Vol. 45. Pp. 171-175.

10. Liu P., Yuan B., Yin D., Miao F. Accumulation laws of main medicinal ingredients in different part of Prunella vulgaris L. // Acta Agric. Bor.-Occid. Sin. 2010. Vol. 19. N10. Pp. 137-140.

11. Chen Y., Guo Q., Zhu Z., Zhang L. Changes in bioactive components related to the harvest time from the spicas of Prunella vulgaris // Pharm. Biol. 2012. Vol. 50. N9. Pp. 1118-1122.

12. Zhu Z.B., Yu M.M., Chen Y.H., Guo Q.S., Zhang L.X., Shi H.Z., Liu L. Effects of ammonium to nitrate ratio on growth, nitrogen metabolism, photosynthetic efficiency and bioactive phytochemical production of Prunella vulgaris // Pharm. Biol. 2014. Vol. 52. N12. Pp. 1518-1525.

13. Петрова Н.В., Буданцев А.Л., Медведева Н.А., Шаварда А.Л. Сезонная динамика накопления кофейной, розмариновой, урсоловой и олеаноловой кислот в листьях Prunella vulgaris L. (Lamiaceae) // Раститительные ресурсы. 2015. Т. 51, вып. 3. С. 420-426.

14. Харина Т.Г., Швыдкая Н.В. Онтогенез и возрастные состояния черноголовки обыкновенной на юге Томской области // Природокомплекс Томской области. Биологические и водные ресурсы. 1995. Т. 11. С. 58-62.

15. Барсукова И. Н., Черемушкина В. А. Онтогенез и жизненная форма Prunella vulgaris (Lamiaceae) в Республике Хакасия // Растительные ресурсы. 2014. Т. 50, вып. 3. С. 347-358.

Поступило в редакиию 26 ноября 2015 г.

После переработки 19 января 2016 г. 
Petrova N.V.*, Medvedeva N.A., Budantsev A.L., Shavarda A.L. VARIATION OF CONTENT OF URSOLIC AND OLEANOLIC ACIDS IN LEAVES OF PRUNELLA VULGARIS (LAMIACEAE) GROWING IN NATURE AND IN THE CLIMATIC CHAMBER

Botanical Institute. V.L. Komarova, Russian Academy of Sciences, ul. prof. Popova, 2, St. Petersburg, 197376 (Russia), e-mail: NPetrova@binran.ru

Prunella vulgaris L. (Lamiaceae) contains a variety of structurally diverse natural products, primarily ursolic acid and oleanolic acid, which possess a wide array of biological properties. The seasonal dynamics of the content of ursolic and oleanolic acids have been determined in leaves of Prunella vulgaris L. growing in natural conditions in the North-West of Russia and in the climatic chamber. In the present study, P. vulgaris was harvested at four developmental stages: vegetation, butonization, blossom and fructification. In sample number 1 (plants grown in the climatic chamber), in phase vegetation and phase butonization, ursolic and oleanolic acids is not detected. In plants grown in the climatic chamber, ursolic and oleanolic acids increased since at blossoming and was maximal at fruiting. In the natural conditions plants (in sample number 2 and 3 ) the amount of ursolic and oleanolic acids increased since vegetation to budding, was maximal at blossoming and slightly decrease to fruiting.

Keywords: ursolic acid, oleanolic acid, Prunella vulgaris, Lamiaceae.

\section{References}

1. Rastitel'nye resursy Rossii: Dikorastushchie tsvetkovye rasteniia, ikh komponentnyi sostav $i$ biologicheskaia aktivnost' T. 4. Semeistva Caprifoliaceae-Lobeliaceae [Plant Resources of Russia: Wild flowering plants and their component composition and biological activity. Vol. 4. Family Caprifoliaceae - Lobeliaceae]. St. Petersburg, 2011, 630 p.(in Russ.).

2. Cheung H.Y., Zhang Q.F. J. Chromatogr. A. 2008, no. 1213, pp. 231-238.

3. Golovkin B.N., Rudenskaia R.N., Trofimova I.A., Shreter A.I. Biologicheski aktivnye veshchestva rastitel'nogo proiskhozhdeniia. [Biologically active substances of plant origin]. Moscow, 2001, vol. II, 764 p. (in Russ.).

4. Liu J.J. Ethnopharmacol. 1995, vol. 49, no. 2, pp. 57-68.

5. Liu H.X., Shi Y.H., Wang D.X., Yang G.L., Yu A.M., Zhang H.Q. J. Pharm. Biomed. Anal. 2003, vol. 32, no. 3, pp. 479-485.

6. Du H., Chen X.Q. J. Iran. Chem. Soc. 2009, vol. 6, no. 2, pp. 334-340.

7. Liao L., Liu L., Guo Q.Sh., Wang Z.Y., Chen Y.N. Chin. Herb. Med. 2010, vol. 2, no. 4, pp. 305-311.

8. Chen Y., Guo Q., Kiu L., Liao L., Zhu Z.J. Med. Plants Res. 2011, vol. 5, no. 9, pp. 1749-1755.

9. Chen Y., Zhu Z., Guo Q., Zhang L., Zhang X. Biol. Res. 2012, vol. 45, pp. 171-175.

10. Liu P., Yuan B., Yin D., Miao F. Acta Agric. Bor.-Occid. Sin. 2010, vol. 19, no. 10, pp. 137-140.

11. Chen Y., Guo Q., Zhu Z., Zhang L. Pharm. Biol. 2012, vol. 50, no. 9, pp. 1118-1122.

12. Zhu Z.B., Yu M.M., Chen Y.H., Guo Q.S., Zhang L.X., Shi H.Z., Liu L. Pharm. Biol. 2014, vol. 52, no. 12, pp. 1518-1525.

13. Petrova N.V., Budantsev A.L., Medvedeva N.A., Shavarda A.L. Rastitelnye resursy. 2015, vol. 51, no. 3, pp. 420426. (in Russ.).

14. Kharina T.G., Shvydkaya N.V. Prirodokompleks Tomskoi oblasti. Biol. i vodn. resursy. 1995, vol. 11, pp. 58-62. (in Russ.).

15. Barsukova I.N., Cheremushkina V.A. Rastitelnye resursy. 2014, vol. 50, no. 3, pp. 347-358. (in Russ.).

Received November 26, 2015

Revised January 19, 2016

\footnotetext{
* Corresponding author.
} 